\title{
JIE
}

JOURNAL OF ISLAMIC EDUCATION

Vol. 7 No. I Mei 2022

P-ISSN 2503-5363; E-ISSN 2528-0465

http://www.ejournal.stitmuhbangil.ac.id/index.php/jie

\section{Manajemen Sarana dan Prasarana di Era Disrupsi Sebagai Pendukung Proses Pembelajaran Pasca Pandemi Covid-19}

\author{
${ }^{*}$ Afiful Ikhwan ${ }^{1}$, Sri Nurul Qomariyah ${ }^{2}$ \\ 1,2Universitas Muhammadiyah Ponorogo, Jawa Timur, Indonesia \\ afifulikhwan@gmail.com
}

\begin{tabular}{l}
\hline Informasi Artikel \\
\hline Received: \\
24 Februari 2022 \\
Accepted: \\
25 Februari 2022 \\
Published: \\
25 Februari 2022 \\
Keywords: \\
Infrastructure \\
Management; \\
Disruption Era; \\
Post-Pandemic Learning; \\
Covid-19.
\end{tabular}

\begin{abstract}
In this era of globalization, education is increasingly becoming a primary need that cannot be denied the existence of its importance to assess an individual's quality. Many educational institutions are competing to improve their quality so that parents are interested in sending their sons and daughters there, such as facilities and new flagship programs that do not yet exist in other schools as infrastructure to support the learning process. The study in this paper focuses on the infrastructure management process as a supporter of the learning process at SD Muhammadiyah Inovatif Ponorogo. This study uses a qualitative descriptive approach, data collection techniques from structured interviews, document analysis and observation, data analysis techniques using Miles \& Huberman theory with coding, finding themes and categorized. They check the validity of the data using triangulation; credibility, transferability, dependability and confirmability. The results of the study show that: (a) quality facilities and infrastructure will improve the quality of students in both academic and nonacademic fields; (b) Management of facilities and infrastructure is carried out by planning, procuring, using, maintaining, inventorying, and eliminating school infrastructure; (c) The emphasis on infrastructure management at SD Muhammadiyah Inovatif Mlarak Ponorogo focuses
\end{abstract}


on efforts to support online learning by teachers by upgrading the internet, personal computers $(P C)$, laptops and mobile phones.

Di era globalisasi ini, pendidikan semakin menjadi kebutuhan primer yang tak dapat dibantah keberadaan pentingnya untuk menilai kualitas suatu individu. Banyak lembaga pendidikan berlomba-lomba untuk meningkatkan kualitasnya agar para orangtua tertarik untuk mengirim putra dan putrinya kesana, seperti penambahan fasilitas dan program program unggulan baru yang belum ada di sekolah lain sebagai sarana prasarana pendukung proses pembelajaran. Kajian dalam paper ini berfokus kepada proses manajemen sarana prasarana sebagai pendukung proses pembelajaran di SD Muhammadiyah Inovatif Ponorogo. Penelitian ini menggunakan pendekatan deskriptif kualitatif, teknik pengumpulan data dari wawancara terstruktur, analisis dokumen, dan observasi, teknik analisis data menggunakan teori Miles \& Huberman dengan coding, menemukan tema dan dikategorikan. Pengecekan keabsahan data pakai trianggulasi; credibility, transferbility, depandibility dan confirmability. Hasil penelitian menunjukan bahwa: (a) sarana dan prasarana yang berkualitas akan meningkatkan kualitas peserta didik baik dalam bidang akademik maupun non akademik; (b) Manajemen sarana dan prasarana dilakukan dengan adanya perencanaan, pengadaan, penggunaan, pemeliharaan, inventarisasi, serta penghapusan sarana prasarana sekolah; (c) Penekanan manajemen sarpras di SD Muhammadiyah Inovatif Mlarak Ponorogo berfokus kepada upaya mendukung pembelajaran daring oleh para guru dengan meg-upgrade internet, personal computer (PC), laptop dan handphone.

\section{Pendahuluan}

Perkembangan era globalisasi yang semakin dirasakan efeknya dengan meningkatnya persaingan antar individu di setiap aspek kehidupan menuntut manusia untuk mengembangkan kualitas dirinya. Begitu pula penduduk 
Indonesia yang harus menerima secara terbuka segala perubahan dalam bidang budaya, politik, ekonomi, serta tidak lupa dalam bidang pendidikan yang merupakan pondasi dasar dari kualitas sumber daya manusia itu sendiri (Ikhwan \& Fauzi, 2018).

Karenanya kualitas pendidikan perlu diperhatikan dengan seksama oleh seluruh pihak terutama pelaku pendidikan, karena peradaban akan terus berkembang dan kualitas suatu bangsa sangat bergantung pada kaulitas generasi penerusnya. Jika generasi penerus bangsa ini adalah sosok yang memiliki intelegensi tinggi serta akhlaq yang baik, maka kemajuan bangsa bukan hal yang mustahil untuk dimimpikan karena mereka akan menjadi warga negara yang menjaga negaranya dengan penuh rasa tanggung jawab. Allah telah berfirman sebagai berikut:

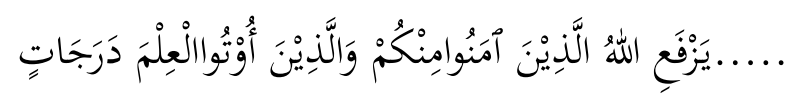

"Allah akan meninggikan derajat orang-orang yang beriman diantara kalian dan orang-orang yang diberi ilmu pengetahuan...." (QS. AlMujadalah: 11) (Al-Fatih, 2009)

Dalam firman tersebut menunjukkan jika seseorang ingin derajatnya naik di mata Allah SWT maka salah satunya haruslah berpendidikan. Bahkan Allah memberikan perintah untuk membaca (belajar) sebagai wahyu yang pertama kali turun dalam surat Al-Alaq ayat 1-5 yang menunjukkan jika pendidikan bukanlah hal dapat diabaikan (M. Taufiq, n.d.).

Pendidikan memiliki tujuan sebagaimana dituangkan dalam UndangUndang Nomor 20 Tahun 2003 Pasal 3 Tentang Sistem Pendidikan Nasional yang berbunyi:

"Pendidikan nasional berfungsi mengembangakan kemampuan dan membentuk watak serta peradaban bangsa bermartabat dalam rangka mencerdaskan kehidupan bangsa, bertujuan untuk berkembangnya potensi peserta didik agar menjadi manusia yang beriman dan bertaqwa kepada Tuhan Yang Maha Esa, berakhlaq mulia, sehat, berilmu, cakap, kreatif, mandiri, dan menjadi warga negara yang demokratis serta bertanggung jawab." (Depdiknas, 2003) 
Pelaksanaan pendidikan yang baik dan benar sangat diharapkan untuk mencapai tujuan pendidikan diatas meskipun itu bukan hal mudah. Akan tetapi jika seluruh pihak turut berpartisipasi dan berkontribusi bersama, maka tujuantujuan yang tertera dalam undang-undang tersebut dapat dicapai dan kualitas kehidupan akan membaik.

Berhubungan dengan hal tersebut di atas, kontribusi pihak terkait seperti guru, anak didik, orang tua, dan pihak lain, fasilitas belajar mengajar juga memberikan pengaruh terhadap keberhasilan proses belajar. Ketersediaan sarana dan prasarana ini memilikii pengaruh besar dalam kelancaran proses manajemen pendidikan sehingga perlu diperhatikan pengelolaannya untuk membantu mencapai kualitas tujuan yang ada baik secara akademik maupun non-akademik (Ikhwan, 2018). Manajemen sarana dan prasarana pendidikan didefinisikan sebagai proses kerjasama pendayagunaan seluruh sarana prasarana pendidikan secara efektif dan efisien (Sinta, 2019).

Banyak sekolah yang memiliki sarana dan prasarana yang sebenarnya lengkap namun tidak bertahan lama karena tidak adanya manajemen yang tepat sehingga justru menghambat kemajuan kualitas pendidikan itu sendiri. Manajemen sarana dan prasarana berfungsi mengatur dan menjagai sarana dan prasarana sehingga dapat mendukung proses pembelajaran secara optimal. Karenanya upaya manajemen sarana dan prasarana diperlukan untuk menjaga kualitas dan kuantitasnya (Qomar, 2007).

Penulis mengutip beberapa penelitian terdahulu sebagai perbandingan dan penegasan pembahasan bahwasannya kajian dalam pembahasan ini mendukung dan melengkapi pembahasan yang telah ada, dan pembahasan dalam kajian ini tidak serta merta hal yang sangat baru, akan tetapi menunjukan dari sisi yang lain yakni peran manajemen sarana prasarana sebagai pendukung inti proses pembelajaran di lembaga pendidikan secara umum, khususnya di lembaga pendidikan Islam serta dengan diskusi dalam kaca mata perspektif Islam.

Pertama, hasil penelitian dari Siti Sofiah tentang Implementasi manajemen sarana dan prasarana Pendidikan Anak Usia Dini (PAUD) yang menghasilkan: 
(a) perencanaan yang meliputi tentang penentuan kebutuhan sarana dan prasarana Raudhatul Athfal (RA), yaitu penentuan anggaran, penentuan sumber daya manusia yang memfasilitasi pengadaan sarpras yang meliputi: pembelian, membuat sendiri, penerimaan hibah, pendaurulangan barangbarang sekolah yang telah usang; (b) pemeliharaan serta penanggungjawab pemeliharaan agar tetap terjaga dengan baik kondisi sarprasnya; (c) pengawasan yang meliputi berapa lama dan berapa kali pengecekan pemeliharaan di lakukan dan siapa saja yang mengecek sarpras yang ada di RA AL-Mu'min Kabupaten Bandung Barat. Ketiga poin tersebut merupakan kesatuan proses manajemen sarana dan prasarana yang dilaksanakan di RA ALMu'min Kabupaten Bandung Barat.

Kedua, penelitian Nurtuah Tanjung tentang Tafsir Ayat- Ayat Alquran Tentang Manajemen Sarana Prasarana yang menghasilkan: bahwa dalam Alquran juga ditemukan ayat-ayat yang menunjukkan bahwa pentingnya sarana dan prasarana atau alat dalam pendidikan. Makhluk Allah berupa hewan yang dijelaskan dalam Alquran juga bisa menjadi alat dalam pendidikan. Seperti nama salah satu surat dalam Alquran adalah an-Nahl yang artinya lebah (Tanjung, 2017).

Ketiga, penelitian Muhlil Musolin tentang Manajemen Sarana dan Prasarana Pendidikan Pondok Pesantren: Studi Kasus Pondok Pesantren An Nawawi Berjan Purworejo yang menghasilkan: putra dari Pondok Pesantren An Nawawi Berjan Purworejo melakukan pengelolaan sarana dan prasarana dengan langkah-langkah: perencanaan dilakukan melalui rapat perencanaan program di Pondok Pesantren An Nawawi; Pengadaan adalah kegiatan pengadaan sarana dan prasarana pesantren sesuai hasil kesepakatan bersama dalam proses perencanaan; inventaris, yaitu semua barang milik pondok pesantren An Nawawi terinventarisasi dengan rapi dalam daftar inventaris barang; Pemeliharaan yaitu pemeliharaan sarana dan prasarana Pondok Pesantren An Nawawi dilakukan oleh seluruh masyarakat yang berada di lingkungan pondok pesantren. Pengawasan dilakukan oleh kepala bagian sarana dan prasarana; Penghapusan dilakukan di Pondok Pesantren An Nawawi 
dengan cara mengganti jika memungkinkan dan mengeluarkan dari daftar inventaris barang.

Dari beberapa hasil penelitian di atas telah banyak dibahas tentang manajemen sarana prasarana secara umum, sebagai pendukung proses pembelajaran belum dibahas sebatas penelusuran yang telah peneliti lakukan. Dengan demikian pembahasan secara mendalam akan dipaparkan pada kajian paper ini tentang bagaimana memanajemen sarana prasarana untuk mendukung proses pembelajaran di Lembaga pendidikan atau sekolah sebagai state of the art pada pembasan manejemen pendidikan khususnya dalam perspektif Islam. Titik fokus pembahasan dalam artikel ini adalah bagaimana manajemen sarana dan prasarana yang baik dapat mempengaruhi dan membantu peningkatan kualitas pembelajaran di sekolah.

\section{METODE PENELITIAN}

Penelitian ini menggunakan pendekatan deskriptif kualitatif untuk mengidentifikasi dan mendeskripsikan manajemen sarana dan prasarana di Sekolah Dasar (SD) Muhammadiyah Inovatif dan keterkaitannya dengan kualitas pembelajaran yang dilaksanakan. Penelitian ini dilakukan di SD Muhammadiyah Inovatif Malarak, Ponorogo, Jawa Timur. Penelitian ini menggunakan wawancara dengan kepala sekolah dan tiga guru sebagai anggota yang biasa mengurusi sarana prasarana di lokasi penelitian. Sedangkan dokumen yang dianalisis adalah list catatan administrasi sarana prasana, program kerja, Rencana Anggaran Belanja (RAB) sarpras 3 tahun terakhir (2019-2021). Selanjutnya, peneliti mengamati proses rapat akhir tahun oleh pimpinan terkait pembahasan sarpras di lokasi penelitian.

Data penelitian diperoleh dari wawancara terstruktur, analisis dokumen, dan observasi. Selain itu, data juga diperoleh melalui Forum Group Discussion (FGD) dengan beberapa anggota pengurus sarpras yang jawaban dan tanggapannya dapat mewakili seluruh nara sumber. Triangulasi dilakukan dari semua data dan meringkas data sesuai dengan masalah penelitian dengan 
menghilangkan data yang tidak perlu. Wawancara direkam dan ditranskrip dengan mengklasifikasikan informasi sesuai dengan tujuan penelitian. Analisis Data dilakukan dengan menggunakan teori Miles \& Huberman dengan tahapan sebagai berikut: reduksi data, penyajian, verifikasi, dan penarikan kesimpulan (Ikhwan, 2020). Selama reduksi data, semua informasi yang tidak perlu dihilangkan. Data dari analisis dokumen, observasi, dan FGD dianalisis dengan coding, menemukan tema dan dikategorikan. Pengecekan keabsahan data pakai trianggulasi; credibility, transferbility, depandibility dan confirmability. Penelitian ini dilakukan selama kurang lebih dua bulan.

\section{TEMUAN DAN PEMBAHASAN}

\section{Temuan Manajemen Sarana Prasana di SD Muhammadiyah Inovatif}

Dalam perkembangan pendidikan, fasilitas merupakan hal yang tak dapat dipisahkan dari setiap proses pembelajaran. Adanya fasilitas ini juga akan memberikan inovasi kepada guru maupun anak didik agar pembelajaran dapat berjalan menyenangkan (Ikhwan et al., 2019).

Sarana dan prasarana pendidikan sendiri memiliki arti yang berbeda. Departemen Pendidikan Nasional memberikan perbedaan antara keduanya. Sarana pendidikan adalah semua peralatan, bahan, dan perabot yang secara langsung digunakan dalam proses pendidikan di sekolah. Dan prasarana pendidikan adalah perangkat kelengkapan dasar yang menunjang pelaksanaan proses pendidikan di sekolah secara tak langsung.

Dalam Peraturan Pemerintah RI No 19 Tahun 2005 Pasal 42, pemerintah telah mengatur susunan standar sarana dan prasarana pendidikan, yaitu; setiap satuan pendidikan wajib memiliki sarana dan prasarana seperti perabot, peralatan pendidikan, media pembelajaran, buku dan/atau sumber belajar lain, ruang kelas, ruang guru dan/atau kepala sekolah, perpustakaan, kantin, tempat olahraga, tempat ibadah sebagai penunjang proses pembelajaran yang teratur dan berkelanjutan (Ariyani, 2018). 
Kelengkapan sarana dan prasarana ini adalah komponen penting dalam pembelajaran dan membantu guru dalam menyelenggarakan kegiatan belajar, sehingga sekolah yang memiliki kelengkapan sarana prasarana ini akan menumbuhkan gairah dan motivasi dalam proses belajar (Sanjaya, 2007). Pengelolaan sarana dan prasarana pendidikan berarti memberi pelayanan profesional dan menciptakan sekolah yang menyenangkan bagi penghuninya serta menyediakan sarana prasaran berkualitas dengan kuantitas yang cukup untuk kepentingan pendidikan. Tujuan manajemen sarana dan prasarana ini antara lain untuk mengupayakan pengadaan sarana prasarana sekolah, mengupayakan pemakaian sarana prasarana yang efisien (Indrawan, 2015) dan mengupayakan pemeliharaan sarana dan prasarana pendidikan hingga selalu dalam kondisi siap pakai setiap kali diperlukan.

Sarana prasana di lokus peneltian yaitu di Sekolah Dasar (SD) Muhammadiyah Inovatif Mlarak Ponorogo tergolong dan termasuk sangat lengkap dan sangat mendukung atau terfasilitasi proses pembelajarannya dari hasil observasi peneliti (Observasi, 2021), dan juga selalu melakukan kajian evaluasi yang terbagi menjadi tiga tahap: evaluasi jangka pendek, menengah dan jangka panjang.

Hasil observasi di atas diperkuat dari pernyataan Kepala Sekolah:

Untuk mengoptimalkan proses pembelajaran di SD Muhammadiyah Inovatif ini tentu kita semua baik dari saya selaku pimpinan dan guru-guru serta stakeholder mengutamakan dan upayakan semaksimal mungkin pemenuhan sarprasnya, karena tidak dipungkiri baik secara nyata maupun teoritis sarpras adalah poin utama yang harus ada dalam melaksanakan dan menjalakan proses pembelajaran, apa lagi di era pandemi atau pasca pandemi kedepan. Terakhir kemarin kita meng-upgrade internet di sini untuk pemenuhan sarpras proses pembelajaran secara daring guru-guru kita, itu kan termasuk sarpras yang tak kasat matam tak terlihat akan tetapi sangat dibutuhkan (Kepala Sekolah, 2021).

Sarana pendidikan diklasifikasikan menjadi tiga; berdasarkan daya tahannya, geraknya, dan hubungannya dengan proses pembelajaran (Barnawi \& Arifin, 2012). Jika dilihat dari daya tahannya maka sarana dibedakan 
menjadi dua yaitu sarana yang habis setelah dipakai dan sarana yang tahan lama. Dan jika dilihat dari geraknya juga dibedakan menjadi dua yaitu sarana yang bergerak sesuai kebutuhan dan tak bergerak atau sulit bahkan tak dapat dipindahkan. Jika dilihat dari hubungan dengan proses pembelajaran dibedakan menjadi alat peraga yang digunakan secara langsung, alat peraga yang mengkonkretkan materi, dana alat peraga yang menjadi perantara proses pembelajaran.

Untuk hasil pembelajaran yang baik, terdapat prinsip yang perlu diperhatiikan dalam pengelolaan sarana prasaran yaitu; prinsip pencapaian tujuan, prinsip efisiensi, prinsip administratif, prinsip kejelasan tanggung jawab, dan prinsip kekohesifan (Indrawan, 2015).

\section{Profil Singkat SD Muhammadiyah Inovatif}

SD Muhammadiyah Inovatif Bajang atau biasa disebut SDMI adalah sekolah yang baru berdiri dan memiliki surat izin resmi pada tahun 2017 terletak di sebelah utara pasar Gandu desa Bajang kecamatan Mlarak Ponorogo. SDMI ini memiliki 11 orang tenaga pengajar dan 1 orang penjaga dengan jumlah anak didik 50 orang dari kelas 1 hingga kelas 4. Gedung SDMI terdiri dari 2 lantai, lantai bawah ada 2 ruang kelas, perpustakaan, kantor, gudang, dan dapur. Untuk lantai atas 1 ruang digunakan untuk kelas dan ruang lain sebagai ruang pertemuan. Jumlah ruang kelas masih akan dilengkapi di tahun kedepannya ketika penerimaan anak didik baru. Kondisi kamar mandi menjadi satu dengan kamar mandi masjid lengkap dengan tempat wudhunya. Lapangan untuk berolahraga belum ada dan sementara kegiatan olahraga dilaksanakan di halaman masjid dan halaman sekolah. Kondisi gedung sekolah dapat dikatakan baik dan terawat. Sarana yang dimiliki oleh SDMI didapat dari dana BOS diantaranya; meja dan kursi, seperangkat komputer, 2 buah laptop, printer, 3 almari, rak buku, buku pelajaran (Dokumentasi, 2021). 


\section{Implementasi Manajemen Sarana Prasarana di SD Muhammadiyah Inovatif Sebagai Pendukung Proses Pembelajaran Pasca Pandemi Covid-19}

Hal pertama yang dilakukan dalam manajemen sarana dan prasarana di Lembaga pendidikan dasar adalah perencanaan dan pengadaan yang dilakukan demi kelangsungan kegiatan pendidikan di sekolah. Perencanaan pengadaan dilakukan melalui ketentuan analisis kebutuhan perlengkapan, perhitungan kisaran biaya, memadukan biaya dan kebutuhan, menunjuk penanggung jawab (Jumari, 2019).

Perencanaan yang dilaksanakan pada akhir tahun pelajaran dengan memilah sarana prasarana mana yang perlu ditambah atau diganti untuk persiapan tahun ajaran baru. Setelah merencanakan segala yang perlu disiapkan, selanjutnya dilakukan pengadaan yang merupakan realisasi dari perencanaan yang telah disusun. Adapun terdapat sebagian besar Lembaga Pendidikan atau Sekolah Dasar yang mendapatakan bantuan dari pemerintah seperti dari Departemen Agama yang sekolahnya berada di bawah naungan Kementerian Agama dan Departemen Pendidikan Nasional yang sekolah dasar umum. Namun itu semua belum dapat memenuhi kebutuhan sekolah seperti jumlah dan ketersediaan terbatas sehingga sekolah harus berinisiatif untuk mengadakan pengadaan sarana dan prasarana yang kurang tersebut.

Sekolah dapat melakukan pengadaan peralatan sekolah tersebut lewat beberapa hal yang dapat dilakukan seperti pembelian dengan memanfaatkan dana Bantuan Operasional Sekolah (BOS) dan kas sekolah, bisa juga sekolah mendapatkan hibah atau sumbangan, dan ada kalanya dengan perbaikan jika dua hal sebelumnya tidak dilakukan (Ikhwan, 2019); (Ikhwan et al., 2020). Dalam pelaksanaan proses pengadaan ini, SD Muhammadiyah Inovatif Malarak Ponrogo melibatkan semua komponen yang ada seperti Kepala Sekolah, para guru, wali siswa, komite sekolah, masyarakat atau stakeholder sekitar SD Muhammadiyah Inovatif Malarak Ponorogo. 
Kemudian, penggunaan secara maksimal adalah pemanfaatan sarana dan prasarana tersebut demi mencapai tujuan pendidikan sesuai visi misi terkini dan sesuai kondisi kebutuhan proses pembelajaran tersebut juga. Sarana prasarana ini pada hakikatnya merupakan tanggung jawab penuh kepala sekolah yang dapat juga melimpahkan pekerjaan ini dengan menunjuk salah satu orang guru dari anggota penanggung jawab bagian sarpras untuk bertanggung jawab (Nurfaza et al., 2020).

Lalu pendistribusian atau kegiatan penyaluran barang dan tanggung jawab dari penanggung jawab kepada pihak yang membutuhkan dengan langkah penyusunan alokasi barang, pengiriman, dan penyerahan barang (Ainiyah \& Husnaini, 2019).

Kemudian investarisasi yang dilakukan dengan mencatat dan menyusun sarana prasarana dengan berkala dan teratur (Maryadi, 2018). Hal ini juga telah diatur oleh pemerintah dan setiap satuan pendidikan harus mempertanggung jawabkannya kepada negara, masyarakat, atau pengguna dengan catatan dalam buku inventaris bagi lembaga pendidikan Negeri (Adnan et al., 2021).

Tidak kalah penting dari setiap hal diatas adalah pemeliharaan. Pemeliharaan harus dilakukan dengan tepat sehingga sarana dan prasarana tersebut dapat langsung digunakan ketika dibutuhkan (siap pakai) dalam proses yang bertanggung jawab atas terpeliharanya sarana dan prasarana ini yaitu seluruh pihak yang ada di sekolah pembelajaran (Fathurrahman \& Putri Dewi, 2019). Jika ada benda-benda yang rawan dengan kerusakan maka ditangani oleh petugas khusus atau pihak ketiga.

Kemudian ada penghapusan sarana dan prasarana dari pertanggung jawaban dengan dasar-dasar yang jelas. Tujuan penghapusan sarana dan prasarana ini adalah mencegah atau setidaknya membatasi pengeluaran biaya pemeliharaan yang berlebih, meringankan tugas pelaksanaan inventaris, menghindari penyempitan ruang karena penumpukan benda yang tak dibutuhkan. Membebaskan pengurus/penanggung jawab dari tanggung jawab barang tersebut (Nurbaiti, 2015). 


\section{Terbantunya Pembelajaran dengan Sarana Prasarana Memadai}

Dalam kegiatan belajar mengajar, sudah pasti ditemui adanya beberapa kendala yang dapat menghambat pemahaman anak didik terhadap materi pelajaran yang diberikan seperti contoh sederhana; meja yang berlubang atau hiasan dinding ruang kelas yang hampir lepas dapat mengalihkan konsentrasi anak didik. Hal yang tampak sepele namun tidak ditangani dengan tepat ini akan mendistraksi perhatian anak didik pada hal-hal diluar pelajaran dan akhirnya tujuan pendidikan tak dapat dicapai dengan optimal.

Jika hal-hal ini terjadi di kelas, maka guru harus mengembalikan fokus anak didik kepada penjelasannya. Guru yang baik adalah guru yang mampu membawa dan menuntun anak didiknya untuk tetap berada dalam fokus yang tepat, pada penjelasan materi yang disampaikannya.

Guru dapat memanfaatkan sarana atau media pembelajaran lain atau yang telah disiapkan untuk menarik kembali perhatian anak didik sehingga kegiatan belajar mengajar dapat berjalan dengan baik kembali. Karena jika permasalahan-permasalahan kecil seperti ini diabaikan, bisa saja justru menimbulkan gangguan yang lebih besar dan mengakibatkan proses pembelajaran menjadi tidak berjalan sebagaimana seharusnya.

\section{KESIMPULAN}

Manajemen sarana dan prasarana memiliki peran sangat penting dalam mendukung kegiatan pembelajaran. Langkah-langkah manajemen sarpras di SD Muhammadiyah Inovatif Malarak Ponorogo dengan (a) perencanaan, (b) pengadaan, (c) penggunaan, (d) pemeliharaan, (e) inventarisasi, dan (f) penghapusan sarana dan prasarana dilakukan dengan bijak akan meningkatkan kualitas pembelajaran di sekolah. Kurangnya manajemen sarana dan prasarana dapat mengganggu dan mendistraksi konsentrasi anak didik dari penjelasan materi guru dan menimbulkan gangguan lain yang lebih besar sehingga tujuan pendidikan tak dapat tercapai. Masih banyaknya sarana dan prasarana yang belum terpenuhi seperti misal bel sekolah dan lapangan olahraga serta kelas 
yang belum lengkap dengan perangkat teknologi yang dibutuhkan di era disrupsi ini, semoga dapat segera dilengkapi untuk kenyamanan belajar bersama.

\section{BIBLIOGRAFI}

[1] Adnan, Mursidin, Jayadi, Suriadi, Ridwan, Y., \& Ikhwan, A. (2021). Education of Religious Characters in Indonesia. Proceedings of the 2nd Annual Conference on Blended Learning, Educational Technology and Innovation (ACBLETI 2020), 560(ACBLETI 2020), 435-440. https://doi.org/10.2991/assehr.k.210615.083

[2] Ainiyah, Q., \& Husnaini, K. (2019). Implementasi manajemen sarana dan prasarana pendidikan dalam peningkatan mutu pembelajaran di sman bareng jombang. Al-Idaroh, 3(2), 98-112.

[3] Al-Fatih. (2009). Mushaf A/-Qur'an Terjemah. PT. Insan Media Pustaka.

[4] Ariyani, R. (2018). Manajemen Sarana Dan Prasarana Dalam Meningkatkan Mutu Pendidikan Di Slb Buah Hati Kota Jambi. Jurnal A/Afkar, 6(2), 110-128.

[5] Barnawi, \& Arifin, M. (2012). Manajemen Sarana dan Prasarana Sekolah. Ar-Ruzz Media.

[6] Depdiknas. (2003). Undang-undang RI No.20 Tahun 2003 tentang Sistem Pendidikan Nasional. Depdiknas.

[7] Dokumentasi. (2021). Dokumentasi SD Muhammadiyah Inovatif Malarak Ponrogo.

[8] Fathurrahman, F., \& Putri Dewi, R. O. (2019). Manajemen Sarana Dan Prasarana Pendidikan Dalam Mendukung Proses Belajar Siswa Di Sdn Puter 1 Kembangbahu Lamongan. Jurnal Reforma, 8(1), 178. https://doi.org/10.30736/rfma.v8i1.141

[9] Ikhwan, A. (2018). Penerapan Manajemen Hubungan Sekolah dan Masyarakat dalam Perspektif Islam. Al-Hayat: Journal of Islamic Education, 2(1), 1-16. http://alhayat.or.id/index.php/alhayat/article/view/19

[10] Ikhwan, A. (2019). Public Relations in an Islamic Perspective; Implementation Study at Madrasah. At-Turats: Jurnal Pemikiran Pendidikan Islam, 13(2), 105-117. https://doi.org/https://doi.org/10.24260/at-turats.v13i2.996

[11] Ikhwan, A. (2020). Metode Penelitian Dasar (Mengenal Model Penelitian dan Sistematikanya). STAI Muhammadiyah Tulungagung.

[12] Ikhwan, A., Fahriana, A. S., Musyarapah, Mukhlis Fahruddin, M., \& Jaelani, 
D. I. (2019). Innovation of Islamic Education Through the Implementation of Mandatory Program Madrasah Diniyah ( Non-Formal Religious Education Institutions ) In Formal Institution. International Conference in Life, Innovation, Change, and Knowladge (ICLICK 2018), 203(Iclick 2018), 320-323. https://doi.org/https://doi.org/10.2991/iclick-18.2019.66

[13] Ikhwan, A., Farid, M., Rohmad, A., \& Syam, A. R. (2020). Revitalization of Islamic Education Teachers in the Development of Student Personality. 1st Borobudur International Symposium on Humanities, Economics and Social Sciences (BIS-HESS 2019). Advances in Social Science, Education and Humanities Research., 436, 162-165. https://doi.org/10.2991/assehr.k.200529.034

[14] Ikhwan, A., \& Fauzi, F. T. (2018). Islam and Civilization: Islam as Source of Value for Human Life. In R. Rohim, A. S. Ahmar, R. Hidayat, \& J. Simarmata (Eds.), WESTECH 2018 (p. 11). EAI: Research Meets Innovation. https://doi.org/10.4108/eai.8-12-2018.2283958

[15] Indrawan, I. (2015). Pengantar Manajemen Sarana dan Prasarana Pendidikan. Deepublish.

[16] Jumari. (2019). Urgensi Manajemen Sarana dan Prasarana Berkualitas Dalam Meningkatkan Kreativitas Peserta Didik. Widya Balina: Jurnal IImu Pendidikan Dan Ekonomi, 4(1), 86-92. https://journal.staidenpasar.ac.id/index.php/wb/article/view/33

[17] Kepala Sekolah. (2021). Wawancara.

[18] M. Taufiq. (n.d.). Al-Qur'an dan Terjemah; Al-Qur'an In Word (1.0.0). Software Quran In Word Versi 1.0.0.

[19] Maryadi, N. (2018). Manajemen Sarana Dan Prasarana Pendidikan Dalam Pembelajaran Di Sd. Jurnal Managemen Pendidikan, 13(1), 15-23.

[20] Nurbaiti. (2015). Manajemen sarana dan prasarana sekolah. Manajer Pendidikan, 9.

[21] Nurfaza, A., Ikhwan, A., \& Nuraini. (2020). The Leadership Role of the Principal as Supervisor in Conflict Management at Muhammadiyah 2 Madiun. Alhayat: Journal of Islamic Education, 4(1), 90-105.

[22] Observasi. (2021). Observasi SD Muhammadiyah Inovatif Malarak Ponorogo.

[23] Qomar, M. (2007). Mujamil Qomar, Manajemen Pendidikan Islam: Strategi Baru Pengelolaan Lembaga Pendidikan Islam. Erlangga.

[24] Sanjaya, W. (2007). Strategi Pembelajaran Berorientasi Standar Proses Pendidikan. Kencana.

[25] Sinta, I. M. (2019). Manajemen Sarana dan Prasarana. ISEMA, 4(1), 7792. https://doi.org/10.15575/isema.v3i2.5645

[26] Tanjung, N. (2017). Tafsir Ayat- Ayat Alquran Tentang Manajemen Sarana 
Prasarana. Jurnal Sabilarrasyad, 2(1). https://jurnal.dharmawangsa.ac.id/index.php/sabilarrasyad/article/view/12 2/117 